DOI: 10.15679/bjwr.v3i1.35

\title{
GENETIC VARIABILITY OF NORTHERN WHITE-BREASTED HEDGEHOGS (Erinaceus roumanicus) FROM SERBIA
}

\author{
Stefanović M. ${ }^{1}$, Veličković $N .{ }^{1}$, Ćosić $N .^{2}$, Ćirović $D .^{3}$, Đan $M .{ }^{1}$
}

Summary: Northern white-breasted hedgehog (Erinaceus roumanicus) is a small mammal distributed in eastern Europe and Ponto-Mediterranean region. Since genetic variability underpins a populations long-term potential for survival and adaptation, the aim of this study was to estimate genetic diversity in E. roumanicus population from Serbia. Partial fragment of mtDNA control region was amplified and sequenced for 74 road killed individuals. In total, 12 haplotypes were detected with haplotype diversity $\mathrm{Hd}=0.827 \pm 0.001$, nucleotide diversity $\pi=0.0036$ and average number of nucleotide differences $\mathrm{k}=1.490$. Spatial clustering of individuals based on the mtDNA variability indicated presence of three groups named approximately after sampling localities as eastern (E), south-central (SC) and southwestern-western-central (SWC) group, with haplotype and nucleotide diversity respectively as follow: $\mathrm{Hd}=0.733 \pm 0.024, \pi=0.0034 ; \mathrm{Hd}=0.897 \pm 0.003$, $\pi=0.0045 ; \mathrm{Hd}=0.725 \pm 0.002, \pi=0.0030$. AMOVA further supported genetic differentiation $\left(\mathrm{F}_{\mathrm{ST}}=0.148, \mathrm{p}=0.002\right)$, even though the most of the variability is due to the within group variation. Eastern group showed higher genetic differentiation (E-SWC $\mathrm{F}_{\mathrm{ST}}=0.221$; E-SC $\mathrm{F}_{\mathrm{ST}}=0.192$ ), while $\mathrm{F}_{\mathrm{ST}}$ value between SC and SWC was 0.106. No shared haplotypes are found between E and two other groups, in contrast to 5 shared of 7 detected in both SC and SWC groups. Mismatch distribution was unimodal, with insignificant SSD values supporting a pattern of demographic expansion, while none of the neutrality tests (Fu's Fs and Tajima's D) was significant, both yielded negative values, except for the group $\mathrm{E}$. The results of this study indicate a moderate genetic diversity and signal of population expansion in E. roumanicus from Serbia.

Key words: E. roumanicus, genetic variability, mtDNA, Serbia

\section{Introduction}

The northern white-breasted hedgehog (Erinaceus roumanicus) is a small nocturnal mammal and the only hedgehog species found in Serbia, distributed in eastern Europe and Ponto-Mediterranean region. In the scientific literature, E. roumanicus was first shortly considered as a subspecies of the west European hedgehog (E. europaeus) generally distributed in western Europe; and later as a subspecies of the southern white-breasted hedgehog (E. concolor), distributed in Asia Minor and Levant (Sommer, 2007; Bolfíková and Hulva, 2012). The studies based on morphological data (Kryštufek, 2002) and genetic data (Santucci et al., 1998; Seddon et al., 2001, 2002; Berggren et al., 2005; Bannikova et al., 2014) supported a sister species status between E. roumanicus and E. concolor, with a divergence time of approximately 1-2 $\mathrm{Myr}$ (Bannikova et al., 2014). The distinct distribution of these three Erinaceus species, as well as their different refugial origins after the Pleistocene, makes them a well-known model in the zoogeography and phylogeography of the Palaearctic (Hewitt, 2000; Sommer, 2007).

Despite the information on biology and ecology of E. roumanicus being scarce, in the view of ecologic preferences no significant differences are known between E. roumanicus and E. europaeus which is far more studied (Sommer, 2007; Bolfíková and Hulva, 2012). As a consequence of human-associated perturbations in the environmental landscape over the last 50 years, including habitat fragmentation,

\footnotetext{
${ }^{1}$ Milomir Stefanović, MSc; Nevena Veličković, PhD; Mihajla Đan, PhD; Department of Biology and Ecology, Faculty of Sciences, University of Novi Sad, Trg Dositeja Obradovića 2, 21000 Novi Sad, Serbia;

${ }^{2}$ Nada Ćosić, PhD, Institute for Biological Research Siniša Stanković, University of Belgrade, Bulevar Despota Stefana 142, 11000 Belgrade, Serbia;

${ }^{3}$ Duško Ćirović, PhD, Faculty of Biology, University of Belgrade, Studentski trg 3, 11000 Belgrade, Serbia.
} 
deforestation and urbanization, the hedgehogs became a synanthropic species, which apart from its natural habitats, such as open deciduous/mixed forests, colonized suburban and urban ecosystems as well (Riber 2006; Dziemian et al., 2010). Even though there is no apparent decline in E. roumanicus population size through its range, studies on E. europaeus indicated rapid decline of this species in some European countries (Holsbeek et al., 1999; Huijser and Bergers, 2000; Orlowski and Nowak, 2004; Hell et al., 2005; Haigh et al., 2014) mainly as a consequence of road fatalities, since hedgehogs are one of the most common mammalian road casualties (Haigh et al., 2014). Apart from the road mortality, populations that inhabit landscape fragments, surrounded by roads and other ecological barriers, are less likely to receive immigrants from other habitats and may suffer from reduced gene flow and inbreeding (Orlowski and Nowak, 2004; Jaeger et al., 2005).

In the response to ever-increasing anthropogenic changes to natural ecosystems, genetic monitoring and identification of management units through usage of different molecular markers is the best estimator of natural populations sustainability, since genetic variability underpins a populations long-term potential for survival and adaptation (Palsbøll et al., 2007; Schwartz et al., 2007). Besides the fact that the phylogeography of hedgehogs is well studied (Santucci et al., 1998; Hewit, 2000; Seddon et al., 2001, 2002), studies of genetic diversity were mostly based on wide samples from Central and Eastern Europe (Seddon et al., 2001, 2002; Bolfíková and Hulva, 2012), and even though these studies did include some samples from the Balkan countries, there were no hedgehog specimens from the territory of Serbia.

Since information on genetic diversity of E. roumanicus from Serbia is lacking, the aim of this study was to analyze variability of mtDNA control region sequences in E. roumanicus population from Serbia and to determine the main population genetic variability parameters in order to estimate its genetic potential for survival and sustainability.

\section{Material and Methods}

The muscle tissue samples from 74 road-killed northern white-breasted hedgehogs were collected in Serbia (Fig. 1) in the period from 2010 until 2014.

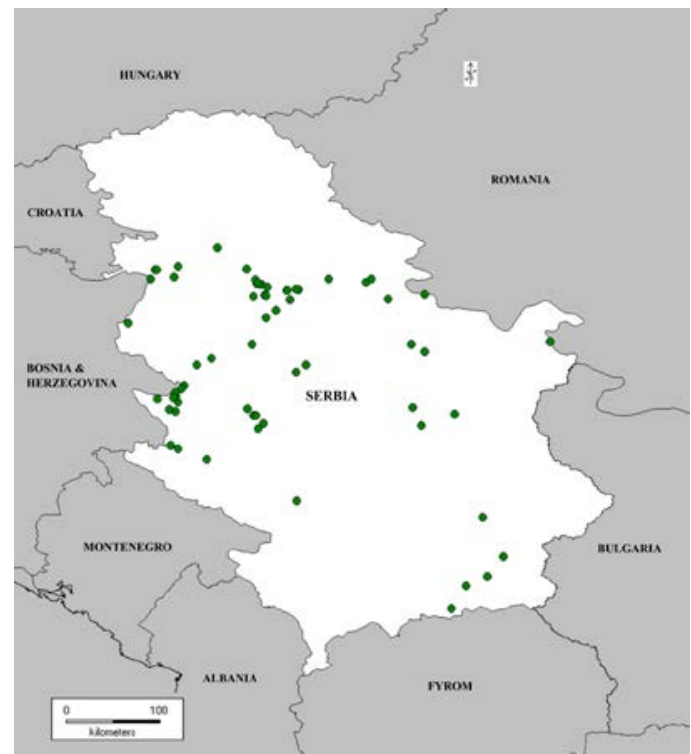

Figure 1: Map of sampling localities of E. roumanicus specimens from Serbia. 
Total DNA was extracted using a slightly modified approach as published by Kocher et al. (1989) and 5'segment of the mitochondrial control region was amplified following procedure published by Seddon et al. (2001) using the primer pair Prol-He and DLH-He. The PCR products were purified following the ExoSAP protocol (Fermentas, Vilnius, Lithuania) and sequenced with an BigDye Terminator v3.1 Cycle Sequencing kit (Life Technologies, Carlsbad, CA, USA) using the forward primer given above.

Obtained sequences were aligned using the Clustal W algorithm (Thompson et al., 1997) implemented in BioEdit 7.0.9.0. (Hall, 1999), and final adjustments were done by eye. The dataset consisted of 74 sequences with the full length of alignment of 420bp. Overall DNA polymorphism parameters (hhaplotype diversity, $\pi$-nucleotide diversity, k-mean number of pairwise differences) were performed in DnaSP v5 (Librado \& Rozas, 2009), while mismatch analysis and neutrality tests (Fu's Fs and Tajima's D test) were performed in Arlequin 3.5.1.2 (Excoffier and Lischer, 2010). Neutrality tests were used as an estimator of population expansion when the null hypothesis is rejected due to the significantly negative values of Fu's Fs $(\mathrm{p}<0.02)$ and Tajima's D $(\mathrm{p}<0.05)$. To estimate possible spatial structuring, Bayesian clustering was assessed using Geneland 3.0 (Guillot et al., 2005). The model for haploid data based on multinomial distribution of genotypes conditionally on allele frequencies, population memberships and linkage equilibrium was used with a total of 1.000 .000 iterations in three independent runs and number of clusters (k) from 1 to 10. DNA polymorphism parameters, neutrality tests and mismatch distribution was also assessed for each detected cluster using DnaSP and Arlequin as described above, with additional calculations of between clusters pairwise $\mathrm{F}_{\mathrm{ST}}$ differences and analysis of molecular variance (AMOVA) in Arlequin.

\section{Results and Discussion}

In total sample of 74 E. roumanicus specimens from Serbia, 12 different haplotypes were detected based on 10 polymorphic sites, of which 9 were parsimony informative and one singleton. One haplotype was common (35.1\%), one was unique, while majority of other haplotypes were presented in low frequencies ranging from 2.7 to $9.46 \%$. Haplotype diversity value (Hd) was $0.827 \pm 0.031$, while nucleotide diversity $(\pi)$ was 0.00356 and the average number of nucleotide differences $(\mathrm{k})$ was 1.490 . Genetic variability of mtDNA CR sequences of E. roumanicus from Serbia showed higher values in comparison with population from Central Europe, where in 55 E. roumanicus specimens five haplotypes were detected with $\mathrm{Hd}=0.289 \pm 0.077$ and $\pi=0.00182$ (Bolfíková and Hulva, 2012).

Spatial clustering of individuals indicated presence of three clusters which are named approximately after the sampling localities as: eastern (E), south-central (SC) and southwestern-western-central (SWC) group (Fig. 2).

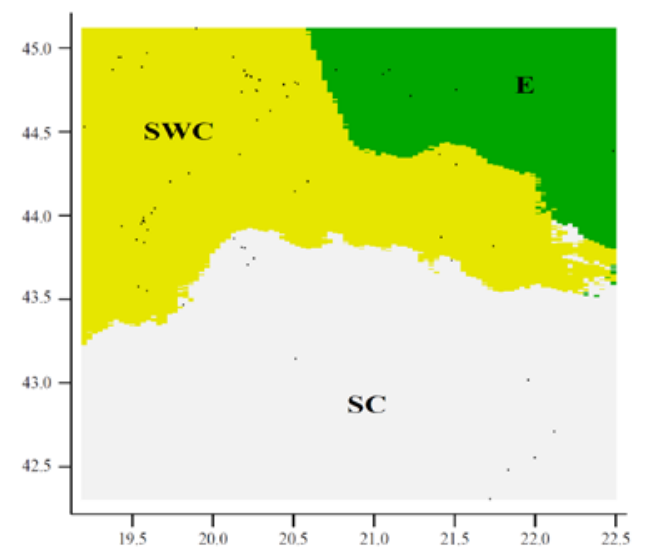

Figure 2: Map of cluster memberships of E. roumanicus individuals from Serbia (E- Eastern cluster; SC South-central cluster; SWC - Southwestern-western-central cluster). 
AMOVA further supported genetic differentiation between those groups $\left(\mathrm{F}_{\mathrm{ST}}=0.148, \mathrm{p}=0.00001\right)$, even though the most of the variability (85.18\%) is due to the within group variation. Eastern group showed the highest genetic differentiation ( $\mathrm{E}-\mathrm{SWC} \mathrm{F}_{\mathrm{ST}}=0.221$ ( $\left.\mathrm{p}=0.007\right)$; $\mathrm{E}-\mathrm{SC} \mathrm{F}_{\mathrm{ST}}=0.192(\mathrm{p}=0.013)$ ), and the lowest number of polymorphic sites and nucleotide diversity $(\pi)$ (Table 1). Pairwise $\mathrm{F}_{\mathrm{ST}}$ value between SC and SWC was 0.106 ( $p=0.013$ ). Gene flow was higher between SC and SWC group (SC-SWC Nm=5.4), in comparison to number of migrants between $\mathrm{E}$ and two other groups $(\mathrm{Nm}=1.8)$. In addition, no shared haplotypes were found between $\mathrm{E}$ and two other groups, in contrast to 5 shared of 7 detected in both SC and SWC groups. All aforestated could indicate a potential genetic isolation of E group. Even though mtDNA is not a suitable molecular marker for detecting contemporary genetic structuring on micro geographical scale, it is noteworthy to mention that the isolation of E group mainly coincides with the only major Serbian high traffic road - European route E75, which may be a cause of the observed isolation.

Table 1: Molecular diversity indices in detected E. roumanicus groups in Serbia

\begin{tabular}{lccc}
\hline & E & SC & SWC \\
\cline { 2 - 4 } Number of samples (n) & 6 & 13 & 55 \\
Number of haplotypes (h) & 3 & 7 & 7 \\
Number of polymorphic sites & 3 & 6 & 7 \\
Haplotype diversity (Hd) & $0.733 \pm 0.155$ & $0.897 \pm 0.054$ & $0.725 \pm 0.044$ \\
Nucleotide diversity ( $\pi$ ) & 0.00334 & 0.00453 & 0.00365 \\
$\begin{array}{l}\text { Average number of pairwise } \\
\text { differences (k) }\end{array}$ & 1.4 & 1.897 & 1.275 \\
\hline E - Eastern group; SC - South-central group; SWC - Southwestern-western-central.
\end{tabular}

Comparison of the observed frequency of mismatch distribution to the expected distribution under the sudden expansion model resulted in insignificant SSD (Sum of Squared Differences) values, therefore failed to reject null hypothesis, thus indicating a past expansion in E. roumanicus population in Serbia (Table 2). Even though not significant, Tajima's D and Fu's Fs values were mostly negative (Table 2) further supporting population growth, while positive only in the E group suggesting a rather stable group. Similar results were in the E. roumanicus population from Central Europe, where moderate population growth was also observed (Bolfíková and Hulva, 2012).

Table 2: Mismatch distribution and neutrality tests in E. roumanicus from Serbia

\begin{tabular}{lcccc}
\hline & E & SC & SWC & Total \\
\cline { 2 - 5 } SSD (p) & $0.034(0.43)$ & $0.031(0.18)$ & $0.002(0.52)$ & $0.003(0.3)$ \\
Tajima's D (p) & $0.338(0.64)$ & $-0.069(0.5)$ & $-0.432(0.39)$ & $-0.732(0.24)$ \\
Fu's Fs (p) & $0.381(0.5)$ & $-2.461(0.03)$ & $-1.039(0.28)$ & $-4.211(0.04)$ \\
\hline
\end{tabular}

E - Eastern group; SC - South-central group; SWC - Southwestern-western-central.

\section{Conclusion}

The Balkans, with its variety of regions and interactions between populations, species and ecosystems, characterizes remarkable genetic diversity, shaped by historical as well as contemporary evolutionary forces (Savić, 2008). Understanding of the genetic diversity and population structure contributes to assessing potential for population's survival and adaptation, delineation of management units and development of sustainable management plans. Results of this study indicate a moderate genetic diversity and a signal of past population expansion of E. roumanicus from Serbia, as well as shallow genetic structuring, with apparent genetic isolation of the Eastern group. Further genetic analysis should include more informative molecular markers, such as microsatellites, in order to perform fine scale in depth structure analyses and in that way contribute to better understanding of anthropogenic and habitat fragmentation effects on northern white-breasted hedgehog population from Serbia. 


\section{Acknowledgment}

The work was financially supported by the Ministry of Education, Science and Technological Development, Republic of Serbia, Grant No. 43002 and the Provincial Secretariat for Science and Technological Development, Grant No. 114-457-2173/2011-01.

\section{References}

1. Bannikova, A.A., Lebedev, V.S., Abramov, A.V., Rozhnov, V.V. (2014) Contrasting evolutionary history of hedgehogs and gymnures (Mammalia: Erinaceomorpha) as inferred from a multigene study. Biological Journal of the Linnean Society 112(3): 499-519.

2. Berggren, K.T., Ellegren, H., Hewitt, G.M., Seddon, J.M. (2005) Understanding the phylogeographic patterns of European hedgehogs, Erinaceus concolor and E. europaeus using the MHC. Heredity 95: 84-90.

3. Bolfíková, B., Hulva, P. (2012) Microevolution of sympatry: landscape genetics of hedgehogs Erinaceus europaeus and E. roumanicus in Central Europe. Heredity 108: 248-255.

4. Dziemian, S., Piłacińska, B., Bogawski, P., Michalik, J. (2010) Infestation of the Northern white-breasted hedgehog (Erinaceus roumanicus) with Ixodes ticks in urban ecosystems of the city of Poznań.

5. Excoffier, L., Lischer, H. (2010) Arlequin suite ver 3.5: A new series of programs to perform population genetics analyses under Linux and Windows. Molecular Ecology Resources 10: 564-567.

6. Guillot, G., Mortier, F., Estoup, A. (2005) GENELAND: a computer package for landscape genetics. Molecular Ecology Notes 5(3): 712-715.

7. Haigh, A., O'Riordan, R. M., Butler, F. (2014) Hedgehog Erinaceus europaeus mortality on Irish roads. Wildlife Biology 20(3): 155-160.

8. Hall, T.A. (1999) BioEdit: a user-friendly biological sequence alignment editor and analysis program for Windows 95/98/NT. Nucleic Acids Research 41: 95-98.

9. Hell, P., Plavý, R., Slamečka, J., Gašparík, J. (2005) Losses of mammals (Mammalia) and birds (Aves) on roads in the Slovak part of the Danube Basin. European Journal of Wildlife Research 51(1): 35-40.

10. Hewitt, G.M. (2000) The genetic legacy of the Quaternary ice ages. Nature 405: 907-913.

11. Holsbeek, L., Rodts, J., \& Muyldermans, S. (1999) Hedgehog and other animal traffic victims in Belgium: results of a countrywide survey. Lutra 42: 111-119.

12. Huijser, M. P., Bergers, P. J. (2000) The effect of roads and traffic on hedgehog (Erinaceus europaeus) populations. Biological Conservation 95(1): 111-116.

13. Jaeger, J. A., Bowman, J., Brennan, J., Fahrig, L., Bert, D., Bouchard, J., Charbonneau, N., Frank, K., Gruber, B., von Toschanowitz, K. T. (2005) Predicting when animal populations are at risk from roads: an interactive model of road avoidance behavior. Ecological Modelling 185(2): 329-348.

14. Kocher, T.D., Thomas, W.K., Meyer, A. (1989) Dynamics of mitochondrial DNA evolution in animals: amplification and sequencing with conserved primers. Proceedings of the National Academy of Sciences USA 86(16): 6196-6200.

15. Kryštufek, B. (2002) Cranial variability in the Eastern hedgehog Erinaceus concolor (Mammalia: Insectivora). Journal of Zoology 258: 365-373.

16. Librado, P., Rozas, J. (2009) DnaSP v5: A software for comprehensive analysis of DNA polymorphism data. Bioinformatics 25: 1451-1452.

17. Orlowski, G., Nowak, L. (2004) Road mortality of hedgehogs Erinaceus spp. in farmland in Lower Silesia (south-western Poland). Polish Journal of Ecology 52(3): 377-382.

18. Palsbøll, P. J., Berube, M., Allendorf, F. W. (2007) Identification of management units using population genetic data. Trends in Ecology \& Evolution 22(1), 11-16.

19. Riber, A. B. (2006) Habitat use and behaviour of European hedgehog Erinaceus europaeus in a Danish rural area. Acta Theriologica 51(4): 363-371.

20. Santucci, F., Emerson, B.C., Hewitt, G.M. (1998) Mitochondrial DNA phylogeography of European hedgehogs. Molecular Ecology 7: 1163-1172.

21. Savić, I.R. (2008) Diversification of the balkan fauna: its origin, historical development and present status. In: Makarov, S.E., Dimitrijević, R.N. (Eds). Advances in Arachnology and Developmental Biology: papers dedicated to Prof. Dr. Božidar Ćurčić. Belgrade: Institute of Zoology, Faculty of Biology; Sofia: BAS; Vienna: Faculty of Life Sciences; Belgrade: SASA; UNESCO MAB Serbia. pp 57-78.

22. Schwartz, M. K., Luikart, G., Waples, R. S. (2007) Genetic monitoring as a promising tool for conservation and management. Trends in Ecology \& Evolution 22(1): 25-33.

23. Seddon, J.M., Santucci, F., Reeve, N.J., Hewitt, G.M. (2001) DNA footprints of European hedgehogs, Erinaceus europaeus and E. concolor: Pleistocene refugia, postglacial expansion and colonization routes. Molecular Ecology 10: 2187-2198.

24. Seddon, J.M., Santucci, F., Reeve, N.J., Hewitt, G.M. (2002) Caucasus mountains divide postulated postglacial colonization routes in the white-breasted hedgehog, Erinaceus concolor. Journal of Evolutionary Biology 15: $463-467$.

25. Sommer, R.S. (2007) When east met west: the sub-fossil footprints of the west European hedgehog and the northern whitebreasted hedgehog during the Late Quaternary in Europe. Journal of Zoology 273: 82-89. 
26. Thompson, J.D., Gibson, T.J., Plewniak, F., Jeanmougin, F., Higgins, D.G. (1997) The Clustal W windows interface: flexible strategies for multiple sequence alignment aided by quality analysis tools. Nucleic Acids Research 25(24): 48764882.

Received: 25.10.2015.

Accepted: 11.12.2015.

Stefanović M. , Veličković N., Ćosić N., Ćirović D., Đan M. (2016). Genetic variability of northern white-breasted hedgehogs (Erinaceus roumanicus) from Serbia, Balkan Journal of Wildlife Research, 3(1), pp. 1-6. 